\title{
An Action Research on Improvement of Reading Comprehension of CET4
}

\author{
Jian-ping Luo ${ }^{1}$ \\ ${ }^{1}$ Guangdong University of Petrochemical Technology, China \\ Correspondence: Jian-ping Luo, College English Department, Guangdong University of Petrochemical \\ Technology, Maoming, Guangdong, 525000, China. E-mail: lm2923302@126.com
}

Received: January 24, 2013 Accepted: February 7, 2013 Online Published: March 10, 2013

doi:10.5539/elt.v6n4p89 URL: http://dx.doi.org/10.5539/elt.v6n4p89

\begin{abstract}
This action research is aiming at improvement of reading comprehension of College English teaching and learning, which is a major time-consuming course with low efficiency in colleges and universities in China. The research subjects were 134 first-year college students of science, engineering and liberal arts, who were from either developed provinces or developing ones. The reading materials used for this research were from passages of reading comprehension of CET4 of each year. This action research went through two stages, at the first of which it focused on improvement by skills-based teaching, but with not much improvements obviously, and at the second of which, after a deep analysis, it combined with text-based teaching and introduced linguistic and schematic knowledge, and finally achieved a good improvement of reading ability with the result showing significant difference, compared with that of the first stage.
\end{abstract}

Keywords: action research, reading comprehension, College English, CET4, China

\section{Introduction}

\subsection{Low Efficiency of College English Teaching and Learning}

In China, College English (CE) is one major compulsory foreign language course for all students at the first two years in colleges and universities, according to the latest College English Curriculum Requirements (CECR) set by the Chinese Minister of Education (2007), which claims that College English, an integral part of higher learning, is a required basic course for undergraduate students. In fact, since 1980s English has already become one of the most strategic courses to the national civil education, and thus is the one that takes up much larger number of teaching hours than any other academic courses (Huang \& Luo, 2011.9).

However, the most time-consuming course is also the one least efficient from then on. Most Chinese students who have spent over ten years on learning English from primary school to college still cannot speak or listen or read or even write the language, let alone fluently. One of the strong evidence is the poor scores from College English Test Band 4 \& 6, which began in the mid of 1980s, and now are given twice every year. Take the result of CET4 given in June 25, 2012 as an example in the following Table 1:

Table 1. June 25, 2012 CET4 Results of Grade 2010

\begin{tabular}{|c|c|c|c|c|c|}
\hline & Total & Listening & Reading & Writing & Integrating \\
\hline 1 est-takers from & $\begin{array}{l}\text { score } \\
\text { (SD) }\end{array}$ & $\mathrm{M} \quad(\mathrm{SD})$ & $\mathrm{M} \quad(\mathrm{SD})$ & $\mathrm{M} \quad(\mathrm{SD})$ & $\mathrm{M} \quad(\mathrm{SD})$ \\
\hline GDUPT & $405(50)$ & $132(23)$ & $152(21)$ & $78(14)$ & $43 \quad(9)$ \\
\hline $\begin{array}{l}\text { Province } \\
\text { Guangdong }\end{array}$ & $409(56)$ & $136(25)$ & $151(23)$ & $80(14)$ & $42 \quad(9)$ \\
\hline All universities & 394 (59) & $127(25)$ & $149(24)$ & $77(16)$ & $42 \quad(9)$ \\
\hline 211 universities & 415 (69) & $135(30)$ & $155(27)$ & $81(17)$ & $43(10)$ \\
\hline Non-211 universities & $392(58)$ & $126(25)$ & $148(24)$ & 77 (16) & $41 \quad(9)$ \\
\hline
\end{tabular}

Notes: The results are from the report by College English Test Band 4 \& 6 Service of East and South Districts of China. The universities mentioned are those in the districts. GDUPT is the short form of Guangdong University 
of Petrochemical Technology, where this writer teaches. "211 universities" refers to the key universities.

$\mathrm{M}=$ mean; $\mathrm{SD}=$ standard deviation; Integrating is for Integrating skills.

In the norm of CET4 \& 6 , full score is 710 , mean is 500 , SD is 70 , and the pass score is 425 , above which the candidate is entitled to take CET6.

For full score of language skills, listening is 249 , reading is 249 , writing is 142 , integrating is 70 .

From Table 1, it is not difficult to see that the results even from the key universities are far not as satisfactory as expected. And it is also not difficult to imagine what a poor efficiency of both teaching and learning of English in China remains. But even so, you can still find at colleges and universities every day that young learners are struggling hard, dreaming to get themselves past the TEST, as more and more enterprises regard the certification of CET4 \& 6 as one crucial standard when they employ new workers (Wang Shouren, 2011).

\subsection{Puzzles of CE Teaching and Learning Research}

Facing these poor results of CET4 \& 6, Chinese scholars of foreign languages have been researching hard, hoping to make remarkable positive contributions and put up guideline for how to improve CE teaching and learning for classroom teachers. But quite a many scholars, especially some influential ones, are only enthusiastic about talking more macro theories than practical research. For nearly thirty years, they have never been tired of arguing again and again, just like grannies, about CE teaching's goal (Cai Jigang, 2010, 2012 a), aims (Shu Dingfang, 2011), orientation (Cai Jigang, Liao Leichao, 2010), re-orientation (Cai Jigang, 2012 b), planning (Hu Wenzhong, 2011), and critical thinking (Sun Youzhong, Li Liwen, 2011). We do not know how these empty talks could help. But we do know CE teaching remains inefficient so far in our country.

We also do know, therefore, in such atmosphere of empty talks, it is common to find from so-called key journals of foreign languages of China that many papers are full of vague theories instead of an actual analysis, even though they are titled as a certain specific analysis. One paper, for example, named as a register analysis of CE classroom discourse, did not even present a single detailed analysis but only the full length of theories (See Page 76-87 in 2012(4) Issue of Foreign Language World). Another paper with a title as a critical discourse analysis of Chinese students' SMS did not demonstrate any real analysis but only three messages as examples for empty theory talking (See Page 27-30 in 2012.2 Issue of Foreign Language Education).

What could we learn from such empty researches? And how should we do our research for improvement? Who know the answer? Our classroom teachers have been long kept in a puzzle about what we really need. Wang Chuming (2012) of Guangdong University of Foreign Studies recently criticizes that we have never been in short of big talks of theories, and what we need to improve CE teaching and learning is an efficient and practical research based on useful theories. What he says goes straight to the heart of the matter. Some other influential scholars all the time do keep on empirical study of English learning, like Wang Chuming (2012) and Xu Jinfen (2010). CE teaching and learning in China today needs more practical application researches, experimental investigations, empirical studies, and classroom action researches than big talks

\subsection{Necessity of Action Research on CE Teaching and Learning}

From the CET4 data, we only know the poor performance of our learners, but could not find and analyze the causes, since College English Testing Band $4 \& 6$ Service has never told us anything more than the scores. Thus, it is necessary for a classroom teacher to do action research to find out what's wrong with their teaching activities, and then make improvement, for "action research is aimed at changing things, and leads to improvement" (Nunan, 2002: 18).

Action research includes three major steps (which can be further divided into six or more minor steps): the first is finding a problem and making a preliminary investigation; and the second is forming a hypothesis and taking a number of strategies for improvement action; the third is reviewing and evaluating the results and running a workshop for discussion. After that, the action research goes on a new cycle, in which the teacher reflects on, returns to, and extends the initial inquiry (Nunan, 2002: 18).

\subsection{Questions of this Research}

(1) What difficulties could be found from investigations that caused low efficiency of reading comprehension?

(2) What and how should classroom teachers do to deal with the found problems and achieve improvement of teaching and learning?

(3) What implications and suggestions for CE teaching and learning from this research? 


\subsection{Purposes of this Research}

Reading is one course of CE teaching, the skill of which is in fact more Important than any other language skills that the learners should first develop in China schools. The CE curriculum requires that "students should be able to read, in the main, English texts on general topics at a speed of $70 \mathrm{wpm}$. With longer yet less difficult texts, the reading speed should be at 100 wpm".(The Chinese Ministry of Education, 2007). Accordingly, the progress of reading ability can be observed and measured quantitatively in classroom, which is then chosen for this action research.

The major purpose of the research is to find out what problems the CE learners really have in CET4 reading, and how the classroom teacher should help solve those exposed problems. This research seeks to discover the factors to cause the poor results of CET4 and what strategies to use for improvement of classroom CE teaching.

\section{Investigation}

\subsection{Beginning with a Small Reading Test}

We know the learners got poor scores of CET4, but we do not know the exact cause, because the given scores are too general to learn anything from them. Thus, we have to make a primary investigation by giving a small reading test, which is the reading in depth from the CET4 on June 25, 2012. There are two types of reading comprehension in CET4, one is Scanning and Skimming, the other is Reading in Depth. The latter is further divided into two sub-types, one is reading with word-filling, the other is reading with multiple choice. For reading with multiple choice is two passages with five questions each and each question with four choices. For reading with word-filling is a passage with ten missing words and the test taker are supposed to choose ten words correctly from a word bank of 15 given words, which is found the most difficult to CE learners because their scores of that part are always the lowest.

\subsection{The Participants}

There were 134 participants of my university, (Guangdong University of Petrochemical Technology). They were the second-year students from Provinces of Guangdong, Guangxi, Guizhou, Yunnan, Hunan, Hubei, Anhui, Henan, Shanxi, Gansu, and Inner Mongolia, where some were from developed areas and some were from developing ones. Also, among them, some were students of science and engineering, and some were students of liberal arts. They all just finished one-year course of CE, and would take CET4 after two-year course of CE, according to the usual regulations of CET4 \& 6.

\subsection{The Result}

For space reasons, we omit the two reading passages with multiple choice, and select for analysis the reading passage with word-filling. In the passage (see Appendix I), there are 15 words to be chosen from for filling-in, which are survive, surrounding, serves, reviewed, reported, recession, households, gather, formally, financially, domestic, competition, communities, circling, accumulate. The following are the result of this primary investigation shown in Table 2, with the correct rate of the ten answers

Table 2. Results of the first reading with word-filling $(\mathrm{N}=134, \mathrm{M}=45.3)$

\begin{tabular}{clcrlc}
\hline No. & Answer & $\begin{array}{l}\text { Correct } \\
\text { Rate }\end{array}$ & No. & Answer & $\begin{array}{l}\text { Correct } \\
\text { Rate }\end{array}$ \\
\hline 1 & domestic & $21.2 \%$ & 2 & communities & $22.3 \%$ \\
3 & survive & $49.2 \%$ & 4 & gather & $64.1 \%$ \\
5 & serves & $48.2 \%$ & 6 & surrounding & $52.6 \%$ \\
7 & recession & $30.3 \%$ & 8 & reported & $90.3 \%$ \\
9 & households & $50.3 \%$ & 10 & financially & $25.4 \%$ \\
\hline
\end{tabular}

From the table you can see that the words with a high correct rate of answer are all those often used words, like 'reported' and 'gather', and that the words with a low rate might be those words unfamiliar to the CE learners, like 'recession' and 'financially'. But you may find the lowest are 'domestic' and 'communities', which are also often used words. Why are they still unfamiliar to the learners? That might be because of the language difference. That is, some words (or notions) might seem common in west, but not in China. For example, we might often use the word 'foreign' to describe something out of China, but we seldom use 'domestic' to refer to something particularly in China. So, not strangely, these words, plus with 'community', 'survive' and so on, would often 
sound unfamiliar even difficult to CE learners of China and cause their failure in such tests.

\section{Hypothesis and Intervention}

\subsection{Hypothesis}

A followed up survey conducted in my classroom to find 'why you failed to understand the passage' showed that $86 \%$ of the interviewees attributed their poor reading ability to a too small vocabulary, and meanwhile, $57 \%$ also attributed to a poor grammar knowledge. So, it seemed that the vocabulary and grammar were two major difficulties to cause the poor results, and then we formed our hypothesis that, if the learners improved their vocabulary and grammar, that is to say, to have a larger vocabulary and a good command of grammar, they would raise their scores of reading comprehension significantly. With that, it was time we made a plan and took action.

\subsection{First Intervention}

"Learners' test results are one way to evaluate teaching. Good results should reflect good teaching" (Davies \& Pearse. 2000:181). And poor results must certainly reflect poor teaching and learning. So, we need to take action and do something specific to change things. We made a five-week program of word study and grammar improvement, with a reading test again at the end of the program.

Firstly, we gave a list of suffixes and affixes to help learners understand derivational words, and also guided them to guess the meaning of a derivation coming cross in their reading.

Secondly, we gave a vocabulary of often-used words based on corpus for them to memorize, and also guided them to guess the meaning of a new word by the context.

Thirdly, we guided the learners to analyze the part of speech of the 15 given word to be filled in a blank in the reading materials.

Also, we organized group activities in class for brainstorm to enhance their vocabulary and grammar.

\subsection{Results after the Five-Week Program}

After the five-week program, there was a reading test again. The reading materials were the same kind of reading in depth but this time from the CET4 on December 17, 2011. Table 3 is the test results of the reading passage with word-filling (see the passage in Appendix II).

Table 3. Results of the second reading with word-filling $(\mathrm{N}=134, \mathrm{M}=49.0)$

\begin{tabular}{clcrlc}
\hline No. & Answer & $\begin{array}{l}\text { Correct } \\
\text { Rate }\end{array}$ & No. & Answer & $\begin{array}{l}\text { Correct } \\
\text { Rate }\end{array}$ \\
\hline 1 & growth & $43.5 \%$ & 2 & stable & $53.8 \%$ \\
3 & challenges & $69.2 \%$ & 4 & certainly & $52.3 \%$ \\
5 & role & $92.3 \%$ & 6 & combined & $40.6 \%$ \\
7 & significant & $26.1 \%$ & 8 & included & $44.6 \%$ \\
9 & comprise & $30.7 \%$ & 10 & solutions & $36.9 \%$ \\
\hline
\end{tabular}

The results showed a little progress after the five weeks, compared with the first test, as shown in Table 4 of the statistics from SPSS, with the significant difference (below 0.001) as well. But, honestly speaking, the total result was still in a poor stage, because the average score was only 49 and far below the pass score.

Table 4. Paired Samples Statistics and Correlations

\begin{tabular}{lccccc}
\hline & Mean & $\mathrm{N}$ & $\mathrm{SD}$ & Correlation & Sig \\
\hline Reading 1 & 45.3 & 134 & 12.5 & & \\
Reading 2 & 49.0 & 134 & 10.7 & 0.44 & 0.000 \\
\hline
\end{tabular}

The study of the correct answer rate revealed that the distribution was nearly as the same as the primary one. That is to say, the correct rate below or about $30 \%$ still went to the words unfamiliar to the learners, like 'significant', 'comprise', 'solutions' and so on, which would strongly imply that our first program might not 
have hit home and we should go on with a further spiral action research, called by Kemmis and McTaggart (1988).

\section{Evaluation and Further Intervention}

Evaluation is an important step in action research, in which it does not simple mean to tell right from wrong for things done. Running a workshop for discussion or consulting experts for advice can help, but doing a deep analysis from fields like cognitive linguistics, sociology, pedagogic psychology, and even cultural difference is also much significant to both classroom teachers and researchers, for the deep analysis is necessary for their new ongoing cycle of action, which is called 'action research spiral' (Kemmis and McTaggart, 1988). It is obvious that we have not achieved much improvement in the five-week program, partly because of merely dealing with the problems of vocabulary and grammar superficially. To better the result properly needs a depth analysis about reading before taking a further action.

\subsection{Two Types of CE Reading}

CE divides reading into two types: extensive reading and intensive reading. Extensive reading is to train learners' ability to understand the whole of a longer text without focusing much on details, while intensive reading is aiming at "an understanding not only of what the text mean, but of how the meaning is produced. The 'how' is as important as the 'what', for the intensive lesson is intended primarily to train strategies which the student can go on to use with other texts" (Nuttall, 2002: 38).

For CET4 \& 6, scanning and skimming are designed for extensive reading, and reading in depth is for intensive reading. Two kinds of reading skills are needed for reading, i.e. macro-skills and micro-skills. Taken as macro-skills are "scanning text to locate specific information" and "skimming text to obtain the gist" (Hughes, 1989: 116), while as micro-skills are reading between the lines, using context to guess meaning of unfamiliar words, and so on. For CE teaching, it is important to train and enhance the two kinds of reading skills. But for CET, you should remind yourself that it might be sometimes wrong to take it for granted that good score only comes from right reading skills, because "good scores of CET4 \& 6 often have nothing to do with the difficulty of reading, but the questions designed by the designer (Huang \& Luo, 2011). For example, if the ten words to fill in are all high-frequently-used words, you are likely to get good mark, though the reading would be much difficult. But usually CET4 \& 6 would not be like that.

\subsection{Types of Knowledge for Reading}

Hedge (2000: 188-189) suggests six types of knowledge a reader needs to employs in struggling to make sense of a text. They are syntactic knowledge, morphological knowledge, general world knowledge, sociacultural knowledge, topic knowledge, genre knowledge. The first two can be put into the category of language (linguistic, or systemic) knowledge, which "help a reader to decode the language of a text". The other four are together often referred to as schematic knowledge, which "enable a reader to work with the language of the text in order to interpret its meaning".

Back to the small reading test above, for example, let's see how these types of knowledge are applied.

The syntactic knowledge would help to fill in a verb (gather) in "People who 4 _ at its front door" and an adverb (financially) in "on the edge 10 ";

The morphological knowledge would help to tell recession might be a noun and domestic might be a adjective just because of their suffixes, and the first might follow "In the wake of the 7 _ ", and latter might appear in "the nation's largest 1 hunger-relief organization";

The general world knowledge would make you think of a city and towns around it, and then help to fill 'surrounding' in "the city and several of the 6 towns";

The sociacultural knowledge would help you understand what a church or a relief organization would probably do in moving through the reading, so you could choose 'serves' for No 5;

The topic knowledge might help you foresee what the reading might be about from the very beginning, and choose 'communities' for No 2;

The genre knowledge might remind you of a news report, and use 'reported' for "It is 8 that".

\subsection{Further Intervention and the Results}

"Achieving improvement in teaching English is a matter of evaluating" (Davies \& Pearse. 2000: 181). But an action after evaluation matters more. We took some other new strategies to strengthen our teaching of CE reading from three aspects. 
First, we put emphasis on knowledge of cultural difference by enlarging extensive reading. Learners were supposed to use macro-skills to obtain sociacultural knowledge to interest themselves in CE reading. A sense of difference of cultures would help a reader easily out of a puzzle of language points. For example, a passage about AIDS comes with "By the time I reached college, the cat was out of the bag". While some readers were quitted puzzled why the author suddenly mentions a CAT, some other readers quickly responded and said, "Thought I could not catch the exact meaning now, I know the phrase must has a story." The latter would certainly become good readers.

Secondly, we guided the learners to begin reading with questions of 'what' and 'how', so that they could predict what the author would go on and got a better understanding of the reading. For example, a reading begins with:

"The popular notion that older people need less sleep than younger adults is a myth, scientists said yesterday."

We would ask, "Did you notice the word 'myth'?" and "Did you think the author might further tell something different?" Another passage begins with:

"Smart eating goes beyond analyzing every bite of food you lift inside your mouth. In the past we used to believe that specific amounts of individual nutrients were the key to good health."

We would ask what the author might tell next, and how you knew that, and give your reasons.

Thirdly, using context effects (Wang, 2009) is a good strategy for dealing with difficult words or phrases in reading, which needs the knowledge including both linguistic knowledge and schematic knowledge mentioned above.

Besides, we used other strategies like speaking highly of the learners who made progress and encouraged positive attitudes, for "favourable attitudes encouraged more success" (Littlewood, 1990:56).

Before the end of this school term we gave two reading tests to check our efforts. The results were good, with the mean scores over the past line and reaching to 63.7 and, which means the approaches we applied were meaningful and valuable to CE teaching and learning. Table 5 is $t$-test of paired samples of the first and the last reading tests.

Table 5. Paired Samples Statistics and Correlations

\begin{tabular}{lcccll}
\hline & Mean & $\mathrm{N}$ & $\mathrm{SD}$ & Correlation & Sig \\
\hline Reading 1 & 45.3 & 134 & 12.5 & & \\
Reading 4 & 63.7 & 134 & 16.0 & 0.33 & 0.000 \\
\hline
\end{tabular}

After the reading test, we carried out an interview survey, in which a boy wrote: "Before that, I would have a big head when in reading, but now I enjoyed it, for my teacher made me find that reading seemed being interactive with the author, which just interested me in it more." A girl said that skill-based reading helped her with techniques to work out her problems she came across when reading, and text-based reading let her know more about her life. The interviewees most expressed their positive attitude toward this reading training, which reflected that the achievement of the action research was much meaningful and positive to both $\mathrm{CE}$ teaching and learning.

\section{Conclusion}

As stated above, facing poor results of CET4, we chose reading comprehension for our research. We first made a investigation and then laid out a plan and for improvements, and the result appeared a small rise, but was still not satisfactory as expected. After the evaluation, we found that what we had done was far not enough, since reading comprehension involves with many things, and we only took linguistic knowledge into account. Therefore, we made a second round of action research, and achieved a much better result than before, which proved the classroom action research was worthwhile to both CE teachers and researchers.

So, back to the research questions raised in the first part of introduction. The difficulties to cause low efficiency of reading come from both linguistic and schematic knowledge, but the schematic knowledge and proper reading skills weigh much more. A CE teacher could achieve improvement of reading by means of text-based reading as well as skill-based reading, and the former is much more valuable than the latter, for it might more appeal to $\mathrm{CE}$ learners and arouse their interest of reading, since interest is the best teacher.

To the question of implications and suggestions, English teaching and learning is a big thing in China, and the 
low efficiency of the long time is not small then, so that we must do something practical to make changes. Unhealthy tendencies to big theories and empty talks could not save it from poor results, but only actually calming down to do things could achieve improvement. Besides, when new school year comes and we face new students and new things, we should continue to research again since our past successful experience might be out of date and not proper in new situations.

\section{References}

Cai, Jigang, \& Liao, Leichao. (2010). EAP vs. ESP-The Orientation of College English. Foreign Language Education, 2010(6), 47-50, 73.

Cai, Jigang. (2012 a). Reanalysis of the Goal of College English Teaching in the Perspective of Globalization. Foreign Languages and Their Teaching, 2012(3), 5-8.

Cai, Jigang. (2012 b). Testing English for General or Specific Purposes-a Study on the Re-orientation of College English Test. Computer-assisted Foreign Language Education, 2012(4), 27-32.

Davies, Paul, \& Pearse, Eric. (2000). Success in English Teaching. Oxford: Oxford University Press.

Hedge, Tricia. (2000). Teaching and Learning in the Language Classroom. Oxford: Oxford University Press.

$\mathrm{Hu}$, Wenzhong. (2011). Planning for foreign language education is imperative for China. Foreign Language Teaching and Research, 2011(1), 130-136, 160.

Huang, Ling-yan, \& Luo, Jian-ping. (2011. 7). Correlation Analysis of Reading Comprehension in CET4 Based on Corpus. Journal of Shaoguan University, 2011(7), 81-83.

Huang, Ling-yan, \& Luo, Jun. (2011. 9). On CET4-6 and the Strategic Significance of College English Course. Journal of Educational Institute of Jilin Province, 2011(8), 51-52.

Hughes, Arthur. (1989). Testing for Language Teachers. Cambridge: Cambridge University Press.

Kemmis, S., \& R. McTaggart. (1988). The Action Research Planner (3rd ed). Geelong, Australia: Deakin University Press.

Littlewood, William. (1990). Foreign and Second Language Learning. Cambridge: Cambridge University Press.

Nunan, David. (2002). Research Methods in Language learning. Shanghai: Shanghai Foreign Language Education Press.

Nuttall, Christine. (2002). Teaching Reading Skills in a Foreign Language. Shanghai: Shanghai Foreign Language Education Press.

Shu, Dingfang. (2011). The internationalization of higher education and the aims and objectives of CET. Foreign Language Teaching and Research, 2011(1), 137-144, 160.

Sun, You-zhong, \& Li, Li-wen. (2011). CBI, ESP and Reform Orientations of English Education in Chinese Universities. Foreign Language Research, 2011(5), 1-4.

The Chinese Minister of Education. (2007). College English Curriculum Requirements. Shanghai: Shanghai Foreign Language Education Press.

Wang, Chuming. (2009). A Study of the Interrelationship Between L2 Learning Variables and L2 Use. Foreign Languages in China, 2009(5), 53-59.

Wang, Chuming. (2012). Use of the Continuation Task to Improve L2 Learning Efficiency. Foreign Language World, 2012(5), 2-7.

Wang, Shouren. (2011). Some Thoughts on College English Teaching in China. Foreign Language Learning Theory and Practice, 2011(1), 1-5.

Xu, Jinfen, Tang, Fang, \& Liu, Zehua. (2010). A "Three-in-One" Teaching Model for Promoting Freshmen's Autonomous English Learning-An Empirical Study of College English Teaching Reform. Foreign Language Education, 2010(6), 60-64.

\section{Appendix I}

Reading in depth (from the CET 4 on June 25, 2012)

Directions: In this section, there is a passage with ten blanks. You are required to select one word for each blank from a list of choices given in a word bank following the passage. Read the passage through carefully before making your choices. Each choice in the bank is identified by a letter. 
One in six. Believe it or not, that's the number of Americans who struggle with hunger. To make tomorrow a little better, Feeding America, the nation's largest 1 hunger-relief organization, has chosen September as Hunger Action Month. As part of its 30 Ways in 30 Days program, It's asking 2 across the country to help the more than 200 food banks and 61,000 agencies in its network provide low-income individuals and families with the fuel they need to 3

It's the kind of work that's done every day at St. Andrew's Episcopal Church in San Antonio. People who 4 at its front door on the first and third Thursdays of each month aren't looking for God --- they're there for something to eat. St. Andrew's runs a food pantry that 5 the city and several of the 6 towns. Janet Drane is its manager.

In the wake of the $7 \ldots$, the number of families in need of food assistance began to grow. It is $8 \_$that 49 million Americans are unsure of where they will find their next meal. What's most surprising is that $36 \%$ of them live in $9 \ldots$ where at least one adult is working. "It used to be that one job was all you needed." says St. Andrew's Drane. "The people we see now have three or four part-time jobs and they're still right on the edge 10 ,"

Word bank: A) survive B) surrounding C) serves D) reviewed E) reported F) recession G) households $\mathrm{H}$ ) gather $\mathrm{I})$ formally J) financially $\mathrm{K}$ ) domestic L) competition $\mathrm{M}$ ) communities $\mathrm{N}$ ) circling O) accumulate

\section{Appendix II}

Reading in depth (from the CET 4 on December 17, 2011)

Directions: In this section, there is a passage with ten blanks. You are required to select one word for each blank from a list of choices given in a word bank following the passage. Read the passage through carefully before making your choices. Each choice in the bank is identified by a letter.

With the world's population estimated to grow from six to nine billion by 2050, researchers, businesses and governments are already dealing with the impact this increase will have on everything from food and water to infrastructure and jobs. Underlying all this __ $47 \ldots$ will be the demand for energy, which is expected to double over the next 40 years.

Finding the resources to meet this demand in a $\quad 48$ energy security, and will be one of the major _ 49 bio-fuels, wind and solar, to name a few --- are _ 50 , sustainable way is the cornerstone of our nation's of the $21^{\text {st }}$ century. Alternative forms of energy --being funded and developed, and will play a growing $51 \ldots$ in the world's energy supply. But experts say that, even when _ $52 \_$_ alternative energy sources will likely meet only about $30 \%$ of the world's energy needs by 2050 .

For example, even with _ $53 \ldots$ investments, such as the $\$ 93$ million for wind energy development $54 \quad$ in the American Recovery and Reinvestment Act, important alternative energy sources such as wind and bio-fuels _ 55 ___ only about $1 \%$ of the market today.

Energy and sustainability experts say the answer to our future energy needs will likely come from a lot of 56 _--- both traditional and alternative.

$\begin{array}{lllllll}\text { Word bank: A) stable } & \text { B) solutions } & \text { C) significant } & \text { D) role } & \text { E) progress } & \text { F) marvelous } & \text { G) included }\end{array}$

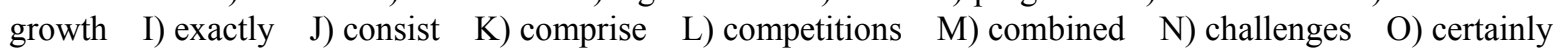

